\title{
Penerapan Metode Simple Queue Pada Manajemen Bandwith untuk Mengoptimalkan Bandwith Di Laboratorium Program Studi Teknik Informatika
}

\author{
Nur'Ain S. Abdullah ${ }^{1}$, Achmad Fuad ${ }^{2}$, Moh. Jamil ${ }^{3}$ \\ Program Studi Teknik Informatika, Fakultas Teknik, Universitas Khairun \\ Jl. Jati Metro, Kota Ternate Selatan \\ E-Mail:ainuti09@gmail.com 1 ad_4ss@yahoo.com ${ }^{2}$,jamil@unkhair.ac.id ${ }^{3}$
}

\begin{abstract}
Service Quality or Quality of Service is a measurement method of how well the network is and is an attempt to define the characteristics and properties of a service. With a bandwidth capacity of 10 Mbps, a measurement is needed to find out how much the service quality is obtained well. In this paper we will discuss a comparison of QOS using the Simple Queue method and before using the Simple Queue method, in that comparison the parameters measured are delay, loss and throughput parameters, these three parameters are tested to compare the better QOS values, the data the test is based on the time specified, namely from 9:00 a.m. to 11:00 a.m., 11: 00-13: 00, 13: 00-15: 00 the test is carried out 3 times in one day then the value is calculated, from the data obtained, third parameters that use Simple Queue have a value with an average value of $0.0302839119 \mathrm{~ms}$ for delay, then throughput has an average value of $858.6 \mathrm{kbps}$ and loss has an average value of $1.308 \%$ with a standardized category that is satisfactory, this proven by the results obtained from the Wireshark application. Then the results of testing the QOS parameters without Simple Queue with the same test method, namely the data tested based on the specified time, namely from 09:00 to 11:00, 11:00 to 13:00, 13:00 to 15:00 testing done in 3 times a day then calculated the value, from the data obtained, the three parameters without Simple Queue have an average value of $0.0134964388 \mathrm{~ms}$ for delay, then throughput has an average value of $483.2 \mathrm{kbps}$ and loss has an average value average of $7.380 \%$ from the results of the QOS parameter using Simple Queue has a more efficient value than the QOS parameterwithout Simple Queue.
\end{abstract}

Keywords:Simple Queue, Delay,Loss,Throughput,Quality Of Service, Management Bandwidth.

Abstrak-Kualitas Layanan atau Quality of Service merupakan metode pengukuran tentang seberapa baik jaringan dan merupakan suatu usaha untuk mendefiniskan karakteristik dan sifat dari suatu servis. Dengan kapasitas bandwidth sebesar 10 Mbps maka diperlukan pengukuran untuk mengetahui seberapa besar kualitas layanan yang didapatkan secara baik. Pada tulisan ini akan dibahas tentang sebuah perbandingan QOS dengan menggunakan metode Simple Queue dan sebelum menggunakan metode Simple Queue, dalam perbandingan tersebut parameter yang diukur merupakan parameter delay, loss dan throughput, ketiga parameter tersebut dilakukan pengujian untuk membandingkan nilai QOS yang lebih baik, data yang uji berdasarkan waktu yang di tentukan yaitu dari jam 09:00-11:00, 11:00-13:00, 13:00-15:00 pengujian dilakukan sebanyak 3 kali dalam satu hari kemudian dihitung nilainya, dari data yang diperoleh, ketiga parameter yang menggunakan Simple Queue memiliki nilai dengan rata-rata nilai sebesar 0,0302839119 ms untuk delay, kemudian throughput memiliki nilai rata-rata sebesar 858,6 kbps dan loss memiliki nilai rata-rata $1,308 \%$ dengan kategori standarisasi tiphon yang memuaskan, hal ini di buktikan dengan hasil yang didapat dari aplikasi wireshark. Kemudian hasil pengujian parameter QOS tanpa Simple Queue debgan cara pengujian yang sama yaitu data yang di uji berdasarkan waktu yang di tentukan yaitu dari jam 09:00-11:00, 11:00-13:00, 13:00-15:00 pengujian dilakukan sebanyak 3 kali dalam satu hari kemudian dihitung nilainya, dari data yang diperoleh, ketiga parameter tanpa Simple Queue memiliki nilai rata-rata sebesar $0,0134964388 \mathrm{~ms}$ untuk delay, kemudian throughput memiliki nilai rata-rata 483,2 kbps dan loss memiliki nilai rata-rata sebesar 7,380 \% dari hasil tersebut parameter QOS dengan Menggunakan Simple Queue memiliki nilai yang lebih efisien dari parameter QOS tanpa Simple Queue

Kata Kunci :Simple Queue, Delay, Loss, Throughput,Quality Of Service, Management Bandwidth. 
JIKO (Jurnal Informatika dan Komputer) Ternate Vol. 03 No. 1, April 2019

\section{PENDAHULUAN}

Jaringan internet merupakan salah satu media teknologi yang sangat berperan penting di era globalisasi, selain merupakan sebuah sarana untuk saling bertukar informasi diberbagai belahan dunia jaringan internet juga merupakan tempat untuk sumber ilmu pengetahuan, dalam beberapa literasi. Pesatnya para pengguna internet membuat akses koneksi internet menjadi lambat atau tidak stabil, sehingga penggunaan internet menjadi tidak maksimal, padahal bandwidth yang tersedia sudah cukup besarHal ini disebabkan karena beberapa karakter pengguna internet yang tidak sama antara satu dengan yang lain, ada beberapa yang sering mengunduh atau mendownload sehingga menghabiskan bandwidth dan ada juga yang hanya sekedar browsing untuk mencari informasi dan chating.[1].

Keberadaan jaringan pada Laboratorium Prodi Teknik Informatika Universitas Khairun ini memiliki beberapa klasifikasi pembagian jaringan, mulai dari jaringan Untuk Laboratorium Jaringan Komputer (LABJAK), Rekayasa Perangkat Lunak (RPL) Dan Laboratorium Riset, dengan beberapa klasifikasi pembagian jaringan tersebut, ini membuat bandwidth yang didapatkan terbagi-bagi kedalam beberapa jaringan, ini membuat bandwidth yang di terima semakin kecil, dan akan mengakibatkan lemahnya sebuah koneksi jaringan di Laboratorium Prodi Teknik Informatika Unkhair tersebut. Untuk meminimalisir drop data drop paket dan keterlambatan sebuah koneksi perlu adanya optimalisasi bandwidth untuk mengontrol sebuah pemakaian bandwidth secara berlebihan oleh client yang terkoneksi di dalam jaringan Prodi Teknik Informatika Unkhair[2].

Optimalisasi bandwidth ini hal yang perlu dilakukan yaitu penetapan jumlah bandwidth pada setiap client jumlah besaran bandwidth yang didapatkan akan disesuaikan dengan jumlah bandwidth yang tersedia, sehingga ketika user atau client melakukan browsing dan melakukan download, pemakaiannya tidak akan melebihi dari kuota bandwidth yang telah ditetapkan. Dengan cara ini pemakaian bandwidth akan terkontrol dan lebih sistematis.

Mikrotik sebagai salah satu vendor hardware dan software yang menyediakan fasilitas untuk Quality Off Service, untuk mengoptimalkan bandwidth agar tetap stabil dan menjaga lalu lintas jaringan agar tidak terjadi kemacetan. Optimalisasi ini dapat dilakukan dengan menggunakan sebuah router. Router adalah perangkat yang akan melewatkan paket IP dari suatu jaringan ke jaringan yang lain, metode pengamatan dan protocol tertentu untuk melewatkan paket data. Konsep dalam analisis kebutuhan
p-ISSN : 2614 - 8897

e-ISSN : $2656-2948$

bandwidth dalam penulisan laporan yang diukur adalah parameterQOS yang meliputi delay, paket loss dan throughput.

Adanya optimalisasi bandwidth ini akan merekomendasikan pengaturan, mekanisme berkaitan dengan pembagian bandwidth yang di maksud.Maka dari itu penulis mengangkat judul "Penerapan Metode Simple Queue Pada manajemen Bandwidth untuk MengoptimalkanBandwidth di Laboratorium Program Studi Teknik Informatika Unkhair"

\section{TINJAUAN PUSTAKA}

A. Jaringan Komputer

Jaringan komputer merupakan sebuah jaringan telekomunikasi yang membolehkan node-node untuk saling berbagi sumber daya (resources). Jadi pada setiap jaringan komputer yang terhubung pada jaringan dapat melakukan pertukaran data dengan komputer lainnya, melalui suatu data link (media kabel atau media nirkabel/wirellse. Menurut Andreww $S$ Tanenbaum, dalam bukunya yang berjudul "Computer Networks $5^{\text {Th }}$ Edition”, , jaringan komputer didefinisikan sebagai berikut: Jaringan komputer adalah kumpulan komputer otonom yang saling terhubung oleh teknologi tunggal.(Sofana, 2017)[4].

B. Sejarah Jaringan Komputer

Dengan semakin luasnya infastruktur jaringan telepon seluler maka jaringan komputer telah memasuki era yang selama ini belum pernah dijangkau, yaitu kolaborasi antara mobile netwok dan komputer network. Setiap orang dapat mengakses internet dimanapun dia berada dengan hanya berbekal sebuah laptop, modem GSM/CDMA, dibanggakan adalah atau Smartphone. Salah satu hasil karya anak bangsa yang patut penemuan teknologi 4G LTEoleh prof. Khairul Anwar teknologi jaringan internet super cepat ini membuat proses transfer data lebih cepat dan lebih (Sofana, 2017)[5].

C. Jenis-jenis Jaringan Komputer berdasarkan jangkauan

1. Lokal Area Network (LAN)

Local area network Yaitu jaringan komputer yang jaringannya hanya mencakup wilayah kecil seperti jaringan komputer kampus, gedung, kantor, dalam rumah, sekolah atau yang lebih kecil dan kawasan jaraknya tidak lebih $1 \mathrm{~km}$ persegi(Yudianto, 2014) 


\section{Gambar 1 Lokal Area Network}

\section{Simple Quеие}

SimpleQueue adalah skenario manajemen bandwidth yang sederhana diterapkan pada jaringan skala kecil sampai menengah untuk mengatur pemakaian bandwidth upload dan download pada setiap user. Dalam skala jaringan sederhana. Pada Simple Queue ini packet classification dan marcking packet tidak wajib untuk dilakukan. Meskipun demikian, Simple Queue juga bisa melakukan manajemen bandwidth terhadap packet-packet yang sudah di-marking. (Rendra, 2014)

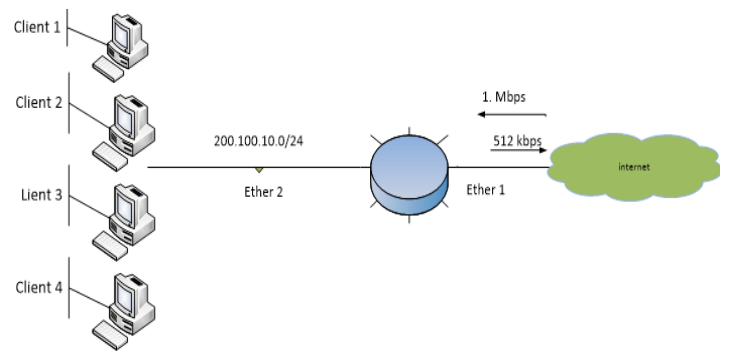

Gambar 4 Cara Kerja Simple Quеuе

\section{E. Quality Off Service}

QOSadalah sebuah kemampuan dari jaringan dalam menyediakan layanan yang baik dengan tingkat jaminan layanan yang berbeda-beda. Yang dimaksud dengan mampu menyediakan layanan yang baik adalah dengan menyediakan kapasitas bandwidth yang layak, mampu mencegah dan mengatasi terjadinya delay, serta mampu mencegah dan mengatasi Loss. Dengan demikian QOS menjadikan suatu aplikasi dapat memberikan layanan seperti yang diharapkan(Pratama, Irwansyah, \& Yulianti, 2015).

\section{F. Delay}

Delay merupakan waktu tunggu atau penundaan waktu dari paket paket yang disebabkan oleh transmisi dari suatu node ke node yang lainnya. Delay yang disebabkan oleh waktu yang diperlukan untuk proses pembentukan paket IP dari informasi user (Tiphon, 2002)

Rumus menghitung delay :

$$
\begin{gathered}
\text { elay rata-rata }=\frac{\text { total delay }}{\text { total paket yang di terima }} \\
\text { Tabel } 1 \text { Kategori Besar Delay }
\end{gathered}
$$

\begin{tabular}{|l|l|}
\hline Kategori Latensi & Besar delay \\
\hline Sangat bagus & $<150 \mathrm{~ms}$ \\
\hline Bagus & $150 \mathrm{~s} / \mathrm{d} 300 \mathrm{~ms}$ \\
\hline Sedang & $300 / \mathrm{d} 450 \mathrm{~ms}$ \\
\hline Jelek & $>450 \mathrm{~ms}$ \\
\hline
\end{tabular}

G. Throughput

Throughput merupakan kecepatan (rate transfer) efektif pengiriman data yang diukur dalam kbps. Troughput merupakan jumlah total kedatangan paket yang sukses yang diamati pada tujuan selama interval waktu tertentu(Tiphon, 2002)

Rumus menghitung Troughput :

$$
\text { Throughput }=\frac{\text { paket data yang diterima }}{\text { lama pengamatan }}
$$

H. Loss

Paket lossadalah jumlah paket data yang hilang per detik. Paket loss dapat di sebabkan oleh sejumlah faktor, mencakup penurunan signal dalam media jaringan, melebihi batas saturasi jaringan, paket corrupt yang menolak transit, dan kesalahan perangkat keras jaringan .(Tiphon, 2002)

Rumus menghitung paket loss :

$$
\text { paket Loss }=\frac{\text { paket data yang dikirim-paket data yang diterima }}{\text { paket data yang di kirim }} \times 100
$$

\begin{tabular}{|l|c|}
\hline \multicolumn{1}{|c|}{ Kategori Degradasi } & Paket Loss \\
\hline Sangat bagus & $0 \%$ \\
\hline Bagus & $3 \%$ \\
\hline Jelek & $15 \%$ \\
\hline Sangat Jelek & $25 \%$ \\
\hline
\end{tabular}

Tabel 2 Kategori Loss

\section{METODE PENELITIAN}

A. Alat dan Bahan

Pada tahap penelitian ini, ada beberapa spesifikasi perangkat penelitian yang harus dipenuhi. Spesifikasi alat penelitian maksudnya adalah standar minimal dari alat (tools) yang digunakan sebagai wadah utama pembuatan sistem guna menjalankan penelitian. Spesifikasi alat pada tabel antara lain sebagai berikut :

Tabel 3 Spesifikasi Hardware

\begin{tabular}{|l|l|l|l|}
\hline $\begin{array}{l}\text { N } \\
\text { O }\end{array}$ & Jenis & \multicolumn{1}{|c|}{$\begin{array}{c}\text { Spesifikasi yang } \\
\text { digunakan }\end{array}$} & Ket \\
\hline 1 & $\begin{array}{l}\text { PC } \\
\text { Serv } \\
\text { er }\end{array}$ & $\begin{array}{l}\text { Dell Inc, model power } \\
\text { edge R230 4 CPUs x 3GHz } \\
\text { Intel @ CPU E3-1220 v5 } \\
\text { @ }\end{array}$ & Server \\
\hline 2 & PC 1 & $\begin{array}{l}\text { Dell Inc, model power } \\
\text { edge R230 4 CPUs x 3GHz } \\
\text { Intel @ CPU E3-1220 v5 }\end{array}$ & Client 1 \\
\hline
\end{tabular}




\begin{tabular}{|c|c|c|c|}
\hline & & @ & \\
\hline 3 & PC 2 & $\begin{array}{l}\text { Dell Inc, model power } \\
\text { edge R230 } 4 \text { CPUs x 3GHz } \\
\text { Intel ® } \text { CPU E3-1220 v5 } \\
\text { @ }\end{array}$ & Client 2 \\
\hline 4 & PC 3 & $\begin{array}{l}\text { Dell Inc, model power } \\
\text { edge R230 } 4 \text { CPUs x } 3 \mathrm{GHz} \\
\text { Intel }{ }^{\circledR} \text { CPU E3-1220 v5 } \\
@\end{array}$ & Client 3 \\
\hline 5 & PC 4 & $\begin{array}{l}\text { Dell Inc, model power } \\
\text { edge R230 } 4 \text { CPUs x 3GHz } \\
\text { Intel ® CPU E3-1220 v5 } \\
@\end{array}$ & Client 4 \\
\hline 6 & PC 5 & $\begin{array}{l}\text { Dell Inc, model power } \\
\text { edge R230 } 4 \text { CPUs x } 3 \mathrm{GHz} \\
\text { Intel } ® \text { CPU E3-1220 v5 } \\
@\end{array}$ & Client 5 \\
\hline 7 & PC 6 & $\begin{array}{l}\text { Dell Inc, model power } \\
\text { edge R230 } 4 \text { CPUs x } 3 \mathrm{GHz} \\
\text { Intel ® CPU E3-1220 v5 } \\
@\end{array}$ & Client 6 \\
\hline 8 & $\begin{array}{l}\text { Mikr } \\
\text { otik }\end{array}$ & RB951Ui-2HnD & Router \\
\hline
\end{tabular}

Tabel 4 Spesifikasi Software

\begin{tabular}{|l|l|l|l|}
\hline No & \multicolumn{1}{|c|}{ Jenis } & Versi & \multicolumn{1}{|c|}{ Keterangan } \\
\hline 1 & OS & $\begin{array}{l}\text { Mikrotik } \\
\text { Router } \\
\text { v6.37.1 }\end{array}$ & Sistem operasi \\
\hline 2 & OS & $\begin{array}{l}\text { Windows } \\
10\end{array}$ & $\begin{array}{l}\text { System operasi } \\
\text { server dan client }\end{array}$ \\
\hline 2 & Winbox & 2.2 .18 & $\begin{array}{l}\text { Di gunakan untuk } \\
\text { remote mikrotik via } \\
\text { GUI }\end{array}$ \\
\hline 3 & Wireshark & V2.2.2.7 & $\begin{array}{l}\text { Di gunakan untuk } \\
\text { mengcapture } \\
\text { jaringan }\end{array}$ \\
\hline
\end{tabular}

\section{B. Desain Sistem}

Desain sistem, pada tahap ini penulis akan melakukan perancangan dari sebuah optimalisasi bandwidth, Simple Queue merupakan perancangan utama dari optimalisasi bandwidth, penggunaan queue dengan sistem dua rate yang berfungsi untuk alokasi bandwidth terendah dan alokasi bandwidth tertinggi. hal ini berfungsi saat jaringan sedang sibuk client akan mendapatkan alokasi bandwidth sesuai dengan jumlah bandwidth yang dibagi rata berdasarkan client yang aktif, sedangkan jika kondisi jaringan sedang sangat sepi, maka client akan mendapatkan alokasi bandwidth tertinggi.

Sistem quеие atau antrian, pada simple queиe, pemisahan paket download dan upload menjadi analisis utama dalam simple queue, penentuan maksimal bandwidth yang di dapat saat client hanya sedikit, dan penentuan bandwidth yang minimal saat client sedang penuh. Perancangan sistem akan dibuat dengan sebuah gambaran topologi untuk menganalisis suatu gambaran tentang optimalisasi bandwidth, selain tahap analisis ini juga untuk mengumpulkan semua data yang menjadi kebutuhan dalam pembuatan sistem untuk proses analisis optimalisasi bandwidth di Laboratorium Proggram Studi Teknik Informatika.

Pada perancangan selanjutnya penulis akan menggunakan aplikasi wireshark untuk menguji sebuah kualitas bandiwidth pada Laboratorium Program Studi Teknik Informatika Unkhair. Pengujian ini dilakukan dengan mengukur suatu kualitas layanan services diantaranya pengukuran terhadap paket Delay, pengukuran terhadap paket Loss serta pengukuran terhadap paket Throughput, pengukuran tersebut bertujuan untuk mengoptimalkan kualitas bandwidth yang ada di Laboratorium Program Studi Teknik Informatika.

\section{Perancangan Simple Queue}

Pada tahap perancangan simple queue merupakan tahapan perancangan awal dalam konfigurasi kinerja bandwidth, dengan membuat konfigurasi queue untuk membuat alokasi bandwidth maksimum yang dapat di gunakan oleh komputer client. Pada tahap awal penentuan pembuatan Ip Address dari komputer client dan besaran alokasi bandwidth yang di berikan, alokasi bandwidth tersebut masih terbagi lagi menjadi alokasi bandwidth untuk upload dan alokasi bandwidth untuk download.

Parameter yang digunakan untuk mewujudkan konfigurasi queue yaitu name yang berfungsi untuk memberikan nama dari quеиe tersebut, target yang berfungsi untuk menentukan berapa IP addres dari client yang akan dibatasi, kemudian parameter maxlimit yang berfungsi menentukan beberapa bandwidth maksimum yang akan didapatkan komputer client tersebut. 


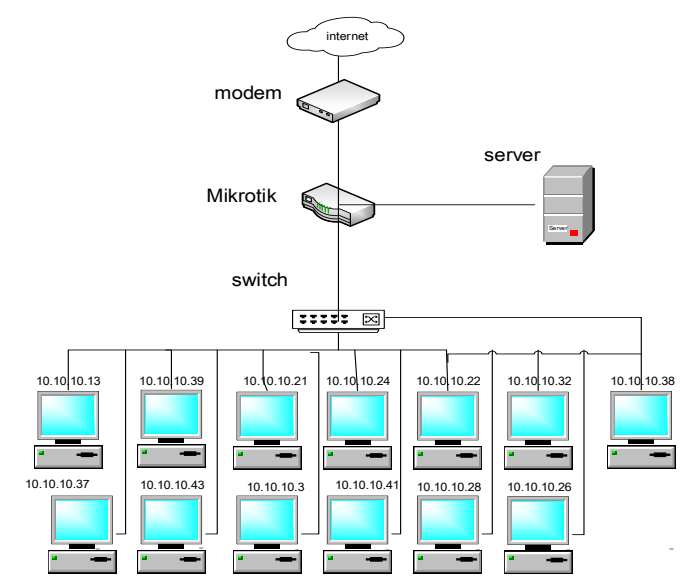

Gambar 5 Topologi Jaringan Teknik Informatika

\section{IV.HASIL DAN PEMBAHASAN}

A. Implementasi

Tahapan implementasi nantinya konfigurasi mikrotik dan penggunaan tools wireshark akan di ukur untuk mengetahui apakah pengukuran bandwidth sudah tepat untuk menunjang kebutuhan sebuah layanan bandwidth untuk mahasiswa. Dengan jumlah bandwidth sebesar 10MB yang terdapat di Laboratorium Program Studi Teknik Informatika maka penulis akan melakukan tahapan awal dengan melakukan konfigurasi pada Mikrotik dengan melakukan setingan pada Simple Queue untuk melakukan manajemen bandwidth, penerapan Simple Queue berfungsi untuk membagi jumlah bandwidth secara merata sesuai dengan jumlah client yang aktif, konfigurasi QOS akan di tetapkan maksimal bandwidth sebesar $10 \mathrm{MB}$, dan untuk limit atau terendah akan di tetapkan berdasarkan hasil pengukuran menggunakan wireshark.

Pengukuran akan dibagi denganskenario pengukuran dengan menggunakan metode Simple Queue dan pengukuran dengan tanpa menggunakan metode Simple Queue, dengan memiliki bandwidth 10 MB akan dilakukan dengan dua skenario. Skenario pertama penulis melakukan pengujian bandwidth menggunakan wireshark tanpa melakukan manajemen bandwidth, dan yang kedua penulis melakukan pengujian untuk optimalisasi bandwidth dengan menggunakan manajemen bandwidth serta menggunakan wireshark untuk menilai parameter QOS diantaranya pengukuran nilai delay, Loss dan, niilai troughput. Kemudian untuk membandingkan kedua pengujian dari Simple Queue dan tanpa Simple Queue, apakah kedua metode mana yang lebih efisien dalam mendapatkan bandwidth yang optimal.

Setelah itu sebagai analisis protocol jaringan selanjutnya penulis melakukan konfigurasi mikrotik, yang meliputi remote mikrotik yaitu tahapan awal untuk mengakses perangkat router, konfigurasi Quick set untuk melakukan konfigurasi secara cepat, kemudian pada tahap selanjutnya penulis melakukan konfigurasi pada Dhcp-client yang berfungsi untuk memperoleh alokasi Ip addres dari ISP, kemudian konfigurasi Ip addres yang berfungsi untuk membuat Ip yang nantinya di peruntukan untuk jaringan lokal, langkah selanjutnya dengan melakukan konfigurasi Dhcp-server agar dapat menyediakan servis atau memberikan layanan Ip addres otomatis bagi client. Kemudian pada tahap selanjutnya dengan melakukan konfigurasi NAT yang berguna untuk mentranslasikan Ip public ke Ip Private, setelah melakukan konfigurasi awal pada mikrotik maka penulis akan melakukan konfigurasi ke tahap selanjutnya yaitu konfigurasi pada Queue

Konfigurasi ini berupa penerapan Simple Queue yang berfungsi untuk menganalisis sebuah kebutuhan bandwidth. Penambahan Simple Queue yang bertujuan untuk melakukan penetapan jumlah bandwidth, mulai dari limit at sampai maximal limit, limit at berfungsi untuk memberikan jumlah bandwidth terendah ketika sedang melakukan pengujian dengan aplikasi wireshark, dan sedangkan untuk maximal limit bertujuan untuk memberikan jumlah bandwidth yang maximal pada saat melakukan pengujian pada aplikasi wiresahrk, dan untuk mengetahui berapa bandwidth yang ideal untuk mahasiswa.

\section{B. Pengujian Parameter}

Dalam pengujian parameter ini, dilakukan untuk mengetahui perbedaan secara lebih akurat kualitas kecepatan bandwidth sebelum dan setelah menggunakan Simple Queue dalam bandwidth management. Dalam pengujian tersebut, penulis melakukan pengujian selama tiga hari dengan 6 komputer, dari masing -masing hari penulis melaukan selama 6 jam mulai dari jam 09:00 pagi sampai jam 15:00 sore . Parameter yang dicari adalah Delay, Throughput, dan Packet Loss.Pengujian dilakukan oleh client menggunakan aplikasi Wireshark yang mana dalam data akan muncul secara otomatis setelah melakukan proses analisa. Hasil data uji yang didapatkan akan disajikan dalam bentuk tabel untuk kemudian disimpulkan dengan grafik.
1. Hasil capture data wireshark sebelum menggunakan Simple Quеие

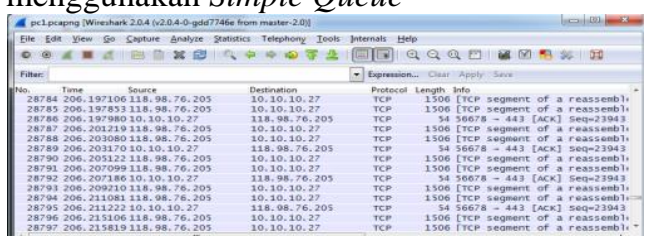


Gambar 6Hasil Capture Data Wireshark Tanpa

\begin{tabular}{|c|c|c|c|c|c|}
\hline \multicolumn{6}{|c|}{ Simple Quеие } \\
\hline Traffic & 1 Captured 1 & Displayed 4 & Displayed \% & 1 Marked 4 & Marked \% 4 \\
\hline Packets & 34660 & 1536 & $4.432 \%$ & 0 & $0.000 \%$ \\
\hline Between first and last pack & ket $371.479 \mathrm{sec}$ & $370.723 \mathrm{sec}$ & & & \\
\hline Avg. packets/sec & 93.303 & 4.143 & & & \\
\hline Avg. packet size & 932 bytes & 200 bytes & & & \\
\hline Bytes & 32310682 & 307552 & $0.952 \%$ & 0 & $0.000 \%$ \\
\hline Avg. bytes/sec & 86978.377 & 829.600 & & & \\
\hline Avg. MBit/sec & 0.696 & 0.007 & & & \\
\hline
\end{tabular}

Gambar 7Tampilan summary wireshark sebelum menggunakan Simple Queue

2. Hasil Capture Data Wireshark Setelah Menggunakan Simple Quеие

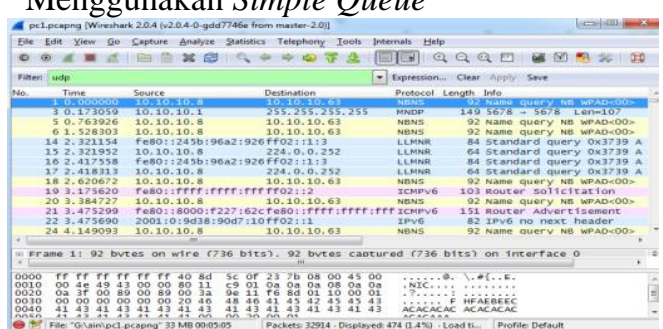

Gambar 8Hasil Capture Data Wireshark Menggunakan Simple Queue

\begin{tabular}{|c|c|c|c|c|c|}
\hline Traffic & I Captured I & 4 Displayed I & 4 Displayed \% & 1 Marked & 4 Marked \% \\
\hline Packets & 32914 & 474 & $1.440 \%$ & 0 & $0.000 \%$ \\
\hline \multicolumn{6}{|c|}{ Between first and last packet $305.193 \mathrm{sec} 305.032 \mathrm{sec}$} \\
\hline Avg, packets/sec & 107.847 & 1.554 & & & \\
\hline Avg, packet size & 993 bytes & 174 bytes & & & \\
\hline Bytes & 32668697 & 82400 & $0.252 \%$ & 0 & $0.000 \%$ \\
\hline Avg, bytes/sec & 107042.905 & 5270.135 & & & \\
\hline Avg. MBit/sec & 0.856 & 0.002 & & & \\
\hline
\end{tabular}

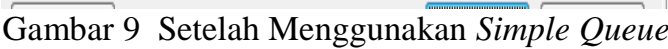

C. Pengujian Delay

1. Pengujian Delay Tanpa Simple Queue

Rata-rata delay = total delay $/$ total paket yang diterima

$$
\begin{aligned}
& =371.479 \mathrm{~s} / 34660 \\
& =0.0107178015 \mathrm{~s} \\
& =10 \mathrm{~ms}
\end{aligned}
$$

2. Pengujian Delay dengan Simple Queue Rata-rata delay $=$ total delay / total paket yang diterima

$$
\begin{aligned}
& =305.193 \mathrm{~s} / 32914 \\
& =0.00927243726 \mathrm{~s} \\
& =9 \mathrm{~ms}
\end{aligned}
$$

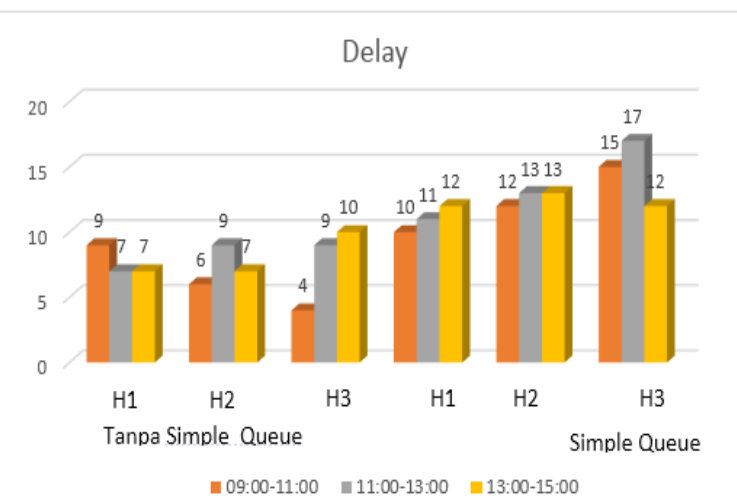

Gambar 10 Grafik Delay

D. Pengujian Throughput

Throughput merupakan kecepatan (rate) transfer data efektif, yang diukur dalam bps. Throughput merupakan jumlah total kedatangan paket yang sukses yang diamati pada destination selama interval waktu tertentu dibagi oleh durasi interval waktu tersebut.

1. Pengujian Tanpa Simple Queue

Throughput $=$ paket data yang diterima / lama pengamatan

$$
\begin{aligned}
& =32310682 / 371.479 \mathrm{~s} \\
& =86978.4486 \text { bytes } / \mathrm{s} \\
& =695.8 \mathrm{kbps}
\end{aligned}
$$

2. Pengujian dengan Simple Queue

Throughput $=$ paket data yang diterima / lama pengamatan

$$
\begin{aligned}
& =32668697 / 305.193 \mathrm{~s} \\
& =107042.747 \text { bytes } / \mathrm{s} \\
& =856,3 \mathrm{kbps}
\end{aligned}
$$

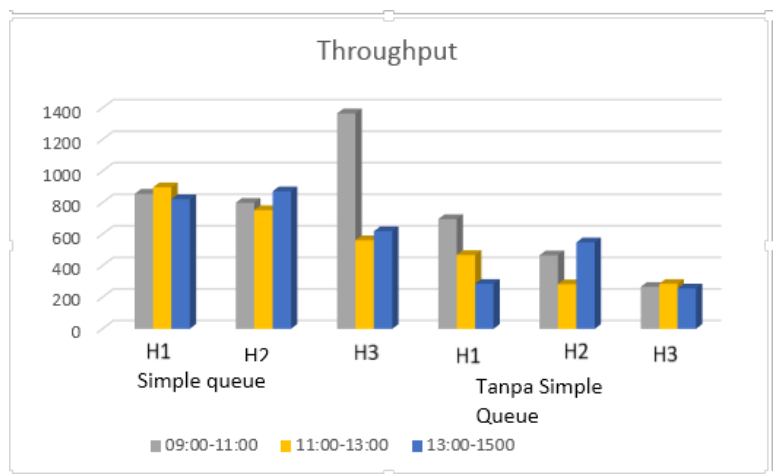

E. Loss 
Packet loss adalah jumlah paket data yang hilang per detik. Packet loss dapat disebabkan oleh sejumlah faktor, mencakup penurunan signal dalam media jaringan, melebihi batas saturasi jaringan, paket yang corrupt yang menolak untuk transit, dan kesalahan perangkat keras jaringan.

\section{Loss tanpa Simple Queue}

paket Loss $=\frac{\text { paket data yang dikirim-paket data yang diterima }}{\text { paket data yang di kirim }} \times 100$

$$
\begin{aligned}
& =\frac{34660-31924}{34660} \times 100 \\
& =1536 / 34660 \times 100 \\
& =4 \%
\end{aligned}
$$

2. Loss dengan Simple Queue paket Loss $=\frac{\text { paket data yang dikirim-paket data yang diterima }}{\text { paket data yang di kirim }} \times 100$

$$
\begin{aligned}
& =\frac{32914-32440}{32914} \times 100 \\
& =474 / 32914 \times 100 \\
& =1 \%
\end{aligned}
$$

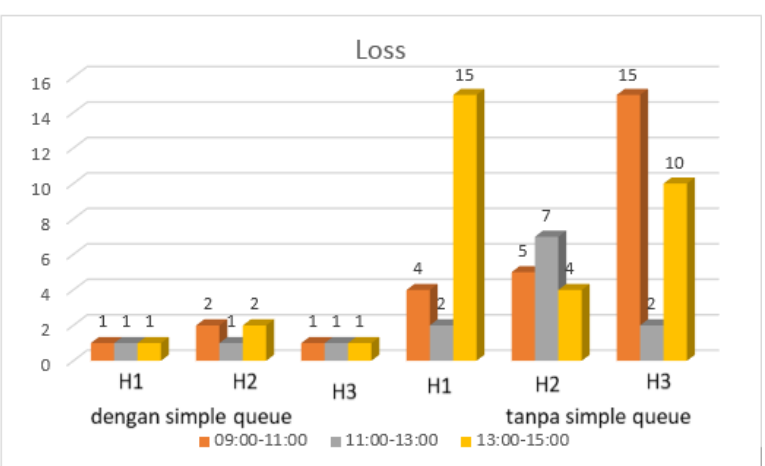

F. Analisis

Gambar 12 Grafik Loss

Berdasarkan tabel hasil penelitian diatas dapat dianalisis bahwa besar delay pada Laboratorium Teknik Informatika dengan menggunakan metode Simple Queue lebih kecil yaitu sebesar $9 \mathrm{~ms}$ sedangkan tanpa menggunakan metode Simple Queue meiliki nilai delay lebih besar yaitu sebesar $10 \mathrm{~ms}$. hal ini dikarenakan kecepatan transfer data dengan menggunakan Simple Queue lebih cepat karena sudah dilakukan pengaturan bandwidth dari setiap client sehingga tidak adanya perebutan bandwidth yang dapat mengakibatkan lambatnya suatu pengiriman data antar server dan client.
Pada perbandingan throughput antara kecepatan yang tidak menggunakan metode Simple Quue dengan menggunakan metode Simple Queue, dapat dilihat bahwa thoughput ketika menggunakan Simple Queue lebih besar yaitu 856,3 kbps sedangkan nilai thoughput tanpa Simple Quеие memiliki nilai sebesar 695, 8 kbps hal itu dikarenakan sudah dilakukan pengaturan bandwidth secara terkontrol yang setiap client sudah mendapatkan jatah bandwidth masingmasing sehingga Throughput dengan menggunkan Simple Queue lebih besar dibandingkan dengan tidak menggunakan Simple Qиеие

Kemudian pada perbandingan Paket loss disimpulkan bahwa nilai loss saat menggunakan metode simple queue memiliki nilai Loss yang kecil yaitu sebesar $1.440 \%$. Sedangkan nilai loss tanpa metode Simple Queue meiliki nilai loss lebih besar yaitu 4,432 \% hal ini dikarenakan protokol yang digunakan adalah TCP yang memiliki kemampuan untuk pengecekan paket data yang hilang ataupun rusak dan mengirimnya kembali, sehingga paket yang loss tidak terlalu besar.

Dengan melakukan pengujian pada parameter QOS dan melakukan perbandingan dengan menggunakan metode Simple Quеие dan tanpa metode Simple Quеие dapat dianalisa bahwa parameter QOS akan lebih maksimal jika parameter QOS di terapkan metode Simple quеие, karena hasil pengukuran di atas paket delay dan loss pada metode Simple Queue lebih kecil, serta nilai throughput lebih besar dibandingkan dengan tanpa metode Simple Queue

Hasil diatas dapat dilihat bahwa kualiatas jaringan dengan menggunakan manajemen bandwidth dengan metode Simple Quеие lebih optimal, hal ini dikarenakan bandwidth akan terbagi sesuai dengan rule yang diterapkan pada manajemen bandwidth dan tidak menyebabkan client saling merebut bandwidth.

\section{KESIMPULAN}

1. Dengan melakukan perbandingan terhadap optimalisasi manajemen bandwidth dengan metode Simple Queue dan tanpa Simple Quеие, penulis telah berhasil mendapatkan parameter $Q O S$ yang lebih baik, yaitu parameter $Q O S$ yang telah dilakukan manajemen bandwidth dengan Simple Quеие jauh lebih ideal yaitu dengan ratarata nilai QOS sebesar 286.646095 dengan indeks 3,6 artinya berdasarkan standarisasi tiphon indeks tersebut, termasuk dalam kategori memuaskan, sedangkan jika di bandingankan dengan tanpa Simple Queue. Nilai rata-rata dari QOS yaitu 
sebesar 163.531165 memiliki indeks 3,5 dengan berdasarkan standarisasi tiphon, nilai rata-rata QOS tanpa Simple Queue juga termasuk kategori memuaskan, tetapi nilai QOS dengan Simple Queue lebih besar dibandingkan dengan tanpa Simple Queue

2. Dengan adanya pengujian parameter $Q O S$ pada Laboratorium Teknik Informatika, serta melakukan perbandingan pada parameter tersebut, penulis dapat mengetahui bandwidth yang optimal setelah melakukan pengujian dengan menggunakan aplikasi wireshark.

3. Dari hasil pengukuran throughput pada manajemen bandwidth dengan menggunakan metode Simple Queue lebih besar yaitu 858,6 kbps sedangkan tanpa metode Simple Quеие sebesar 483,2 kbps

4. Dari hasil pengukuran delay pada manajemen bandwidth dengan menggunakan metode Simple Quеие nilai yang didapatkan yaitu $30 \mathrm{~ms}$ lebih kecil dibandingkan dengan tidak menggunakan Simple Queue yaitu sebesar $134 \mathrm{~ms}$

5. Dari hasil pengukuran paket Loss dapat disimpulkan selama pengujian data yang dilakukan oleh wireshark, pengujian paket loss dengan menggunakan metode Simple Quеие memiliki nilai loss sebesa $1 \%$ lebih kecil dibandingkan dengan pengujian paket loss tanpa Simple Quеие yaiutu sebesar $7 \%$

\section{DAFTAR PUSTAKA}

[1] Pratama, T., Irwansyah, M. A., dan Yulianti. 2015. Perbandingan Metode PCQ, SFQ, RED dan FIFO pada Mikrotik Sebagai Upaya Optimalisasi Layanan Jaringan Pada Fakultas Teknik Universitas Tanjungpura

[2] Rendra, T. 2014. Mikrotik Kitab 3 Rendra, T. (2014). Mikrotik Kitab 3 Manajemen Bandwidth

[3] Sophia, (2002). Telecommunications and Internet Protocol Harmonization Over Networks (TIPHON) Release 3

[4] Sofana, I. (2017). jaringan komputerberbasis mikrotik. bandung: informatika bandung.

[5] Yudianto, M. J. N. (2014). Jaringan Komputer dan Pengertiannya. Ilmukomputer.Com. palu 